\title{
Does Inhibition of Aldose Reductase Contribute to the Anti-Inflammatory Action of Setipiprant?
}

\author{
J. BALLEKOVA ${ }^{1}$, M. SOLTESOVA-PRNOVA ${ }^{1}$, M. MAJEKOVA ${ }^{1}$, M. STEFEK ${ }^{1}$ \\ ${ }^{1}$ Institute of Experimental Pharmacology and Toxicology, Slovak Academy of Sciences, Bratislava, \\ Slovak Republic
}

Received October 19, 2016

Accepted January 25, 2017

On-line April 12, 2017

\begin{abstract}
Summary
The aim of this study was to investigate aldose reductase inhibitory action of setipiprant as a potential additional mechanism contributing to its anti-inflammatory action. Aldose reductase activity was determined by spectrophotometric measuring of NADPH consumption. Setipiprant was found to inhibit aldose reductase/NADPH-mediated reduction of 4-hydroxynonenal, 4-hydroxynonenal glutathione and prostaglandin $\mathrm{H} 2$ substrates, all relevant to the process of inflammation. Molecular modeling simulations into the aldose reductase inhibitor binding site revealed an interaction pattern of setipiprant. Considering multifactorial etiology of inflammatory pathologies, it is suggested that, in addition to the antagonizing prostaglandin D2 receptor, inhibition of aldose reductase may contribute to the reported anti-inflammatory action of setipiprant.
\end{abstract}

\section{Key words}

Setipiprant • Asthma • Aldose reductase inhibition • Inflammation - Androgenic alopecia

\section{Corresponding author}

M. Stefek, Institute of Experimental Pharmacology and Toxicology, Slovak Academy of Sciences, Dubravska cesta 9, 84104 Bratislava, Slovakia. E-mail: Milan.Stefek@savba.sk

\section{Introduction}

Setipiprant, 2-[8-fluoro-2-(naphthalene-1carbonyl)-3,4-dihydro-1H-pyrido[4,3-b]indol-5-yl] acetic acid (Fig. 1), was initially invented as a promising remedy for allergies and inflammatory disorders based on its selective antagonism of the CRTH2 (DP2) receptor
(Fretz et al. 2013, Diamant et al. 2014). As a CRTH2 antagonist, setipiprant may counteract proinflammatory effects of prostaglandin D2 (PGD2) in allergic responses. Yet inadequate efficacy revealed in clinical studies led to termination of the development of setipiprant (Norman 2014). However, the discovery that the levels of both prostaglandin D2 synthase (PTGDS) and its product PGD2 are increased in the scalp of men suffering from androgenetic alopecia (Garza et al. 2012) initiated the development of this drug as a novel treatment for baldness (Cotsarelis et al. 2015).

Setipiprant is a derivative of indole-1-acetic acid. Since compounds of this group are efficient inhibitors of aldose reductase (Van Zandt et al. 2005, Van Zandt et al. 2009, Juskova et al. 2011) we were prompted to investigate the aldose reductase inhibitory activity of setipiprant. Considering the $\mathrm{PgF} 2 \alpha$ synthase activity of aldose reductase isolated from the human placenta and mouse kidney (Kabututu et al. 2009), and more importantly the recently reported PGD2 synthase activity of recombinant human aldose reductase (AKR1B1) and mouse aldo-keto reductase AKR1B3 (Nagata et al. 2011), the aldose reductase inhibitory activity would be of great relevance for potential molecular mechanisms involved in biological action of setipiprant. The issue is also interesting with respect to potential side effects of the drug.

In the light of the above mentioned findings, we considered it interesting to study the aldose reductase inhibitory action of setipiprant in greater detail, and that at the level of isolated rat and human enzymes. 


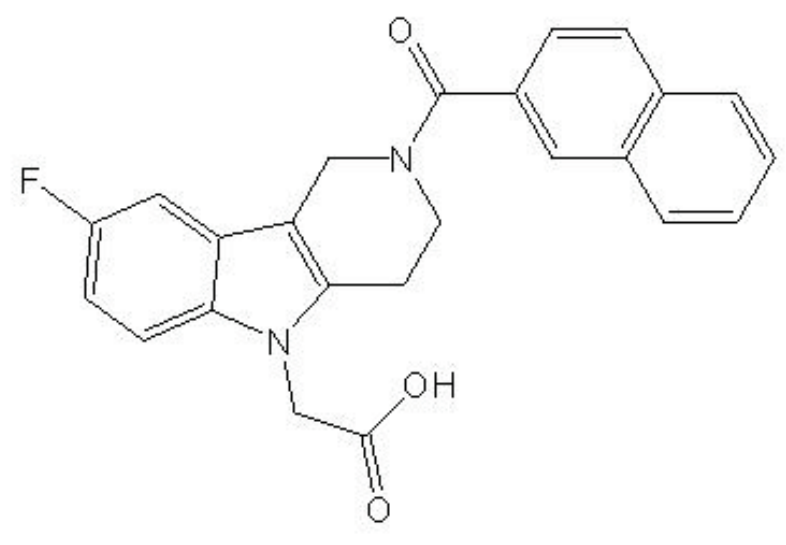

Fig. 1. Chemical structure of setipiprant.

\section{Material and Methods}

\section{Chemicals}

Setipiprant (Cat\# Amb22015120) was obtained from Ambinter c/o Greenpharma 3, Orléans, France. Recombinant human aldose reductase AKR1B1 was kindly provided by Prof. G. Klebe, Philipps-University Marburg, Germany. The protein was expressed and purified using the protocol reported previously (Stefek et al. 2015). D,L-glyceraldehyde, sodium glucuronate, NADPH, D-glucose, $\beta$-mercaptoethanol, 4-hydroxynonenal-dimethylacetal were obtained from SigmaAldrich (St. Louis, MO, USA). 4-hydroxynonenal glutathione (trifluoroacetate salt), prostaglandin $\mathrm{H} 2$ from Cayman Pharma, Neratovice, Czech Republic. Diethylaminoethyl cellulose DEAE DE 52 was from Whatman International Ltd. (Maidstone, England).

\section{Animals}

Male Wistar rats, 8-9 weeks old, weighing 200-250 g, were used. The animals came from the Breeding Facility of the Institute of Experimental Pharmacology, Dobra Voda (Slovak Republic). The study was approved by the Ethics Committee of the Institute and performed in accordance with the Principles of Laboratory Animal Care (NIH publication 83-25, revised 1985 ) and the Slovak law regulating animal experiments (Decree 289, Part 139, July 9, 2003).

\section{Enzyme assays}

Aldose reductase preparation from rat lens and aldehyde reductase purification procedure from rat kidney were reported previously (Stefek et al. 2008). Aldose reductase and aldehyde reductase activities were assayed spectrophotometrically by determining NADPH consumption at $340 \mathrm{~nm}$ and were expressed as decrease of the optical density (O.D.)/s/mg protein as described previously (Stefek et al. 2008). The effect of setipiprant on the enzyme activities was determined by including in the reaction mixture the inhibitor at required concentrations dissolved in DMSO at $1 \%$ final concentration. At the same concentration, the inhibitor was included in the reference blank. The reference blank contained all the above reagents except the substrate to correct for oxidation of NADPH not associated with reduction of the substrate. The enzyme reaction was initiated by addition of a substrate and was monitored for up to $8 \mathrm{~min}$ after an initial period of $1 \mathrm{~min}$. The substrate concentration was set to be minimally 3 times higher than the corresponding $\mathrm{K}_{\mathrm{m}}$. Enzyme activities were adjusted by diluting the enzyme preparations with distilled water so that $0.05 \mathrm{ml}$ of the preparation gave an average reaction rate for the control sample of $0.020 \pm$ 0.005 absorbance units $/ \mathrm{min}$. $\mathrm{IC}_{50}$ values (the concentration of the inhibitor required to produce $50 \%$ inhibition of the enzyme reaction) were determined both from the least-square analysis of the linear portion of the semi-logarithmic inhibition curves and non-linear regression analysis. Each curve was generated using at least four concentrations of inhibitor causing an inhibition in the range from at least 25 to $75 \%$.

\section{Computational methods}

Input conformation of setipiprant was obtained by equilibrium conformer systematic search (MMFF94) performed in the program Spartan 08 (Wavefunction Inc., USA, Shao et al. 2006). The pdb structure with $1 \mathrm{z} 3 \mathrm{n}$ code (protein with $\mathrm{NADP}^{+}$and lidorestat) was taken as a model of human recombinant AKR1B1 to study the enzymeligand interactions. To correct the bonds and hydrogens, the enzyme structure was treated by means of the software Yasara (Krieger et al. 2002). The protonation state corresponding to the experimental $\mathrm{pH}$ value was used. First, setipiprant was immersed into unoptimized complex instead of the lidorestat and docking was performed according to the local docking protocol of Yasara (with 250 runs and $\mathrm{RMSD}_{\min }=5.0 \AA$ ). The obtained clusters were then searched for the minimum of the binding energy $\mathrm{E}_{\mathrm{bin}}$ within the optimization protocol em_run.mcr, which allows optimizing the whole complex by a combination of gradient optimization, simulated annealing and single molecular dynamics calculation. The structure of a ternary complex with the minimum $\mathrm{E}_{\text {bin }}$ value was chosen for the interaction analysis. 
Table 1. Inhibition of aldo-keto reductases by setipiprant.

\begin{tabular}{llccc}
\hline Enzyme & & Substrate $(\mathbf{m M})$ & $\mathbf{K}_{\mathbf{m}}(\mathbf{m} \mathbf{M})$ & $\mathbf{I C}_{\mathbf{5 0}}(\boldsymbol{\mu} \mathbf{M})^{\mathbf{a}}$ \\
\hline \multirow{2}{*}{ Rat lens ALR2 } & Glyceraldehyde & 4.67 & $0.585^{\mathrm{b}}$ & $0.141 \pm 0.053$ \\
& GS-HNE & 0.10 & $0.030^{\mathrm{c}}$ & $1.190 \pm 0.194$ \\
& HNE & 0.50 & $0.030^{\mathrm{d}}$ & $0.571 \pm 0.064$ \\
& Glucuronate & 20.00 & $2.240^{\mathrm{e}}$ & $43.800 \pm 0.080$ \\
Human recombinant AKR1B1 & Glyceraldehyde & 4.67 & $0.092^{\mathrm{f}}$ & $0.038 \pm 0.004$ \\
& PGH2 & 0.02 & $0.124^{\mathrm{g}}$ & $2.076 \pm 0.103$ \\
\hline
\end{tabular}

$\mathrm{HNE}$, 4-hydroxynonenal; GS-HNE, 4-hydroxynonenal glutathione; $\mathrm{PGH} 2$, prostaglandin $\mathrm{H} 2 ;{ }^{a}$ Results are mean values $\pm \mathrm{SD}$ from at least three measurements. ${ }^{b}$ Stefek et al. 2008, ' Srivastava et al. 1998, d Endo et al. 2009, e unpublished results, ${ }^{\mathrm{f}}$ Balendiran et al. 2005, ${ }^{9}$ Kaiserova et al. 2006, ${ }^{\text {h }}$ Kabututu et al. 2009.

\section{Results}

\section{Inhibition of aldo-keto reductases}

As shown in Table 1, setipiprant efficiently inhibited both rat and human recombinant aldose reductase. With glyceraldehyde used as a substrate, the $\mathrm{IC}_{50}$ for inhibition of rat aldose reductase was as low as $141 \mathrm{nM}$; about four times higher efficacy was recorded for setipiprant inhibition of human recombinant AKR1B1. Reduction of HNE, the toxic product of lipid peroxidation, and its physiological glutathione adduct by rat aldose reductase was still very efficiently inhibited by setipiprant, with the respective $\mathrm{IC}_{50}$ values in high nanomolar and low micromolar region.

To test the selectivity of setipiprant inhibitory action, inhibition of rat kidney aldehyde reductase was examined. By using glucuronate as a substrate, the inhibition efficacy of setipiprant was characterized by $\mathrm{IC}_{50}=43.80 \pm 0.08 \mu \mathrm{M}$ (Table 1), giving the selectivity factor of approx. 310 in relation to rat lens aldose reductase.

In the next step, the enzyme kinetics of the inhibitory action of setipiprant was analyzed. As shown in Figure 2, uncompetitive inhibition was observed for rat aldose reductase and glyceraldehyde as a substrate with a corresponding inhibition constant $\mathrm{Ki}=0.065 \pm 0.020 \mu \mathrm{M}$.

\section{Molecular modeling}

The lidorestat-bound conformation of ALR2 (PDB code: 1z3n; van Zandt et al. 2005) was used for docking owing to structural similarity of setipiprant to the ligand lidorestat. The interaction analysis of setipiprant human recombinant AKR1B1 complex revealed efficient triple hydrogen bond connections of setipiprant with
Tyr 48, His 110 and Trp 111 (Fig. 3). Six hydrophobic bonds (Trp 20, Lys 21, Phe 122, Cys 298 and Leu 300) plus one with $\mathrm{NADP}^{+}$created a hydrophobic network stabilizing the position of setipiprant in the binding site supported also by two $\pi-\pi$ interactions (Tyr 48 and Trp 119). Moreover, the parallel interactions of setipiprant with Phe 122 and Leu 300 opened the specificity pocket.

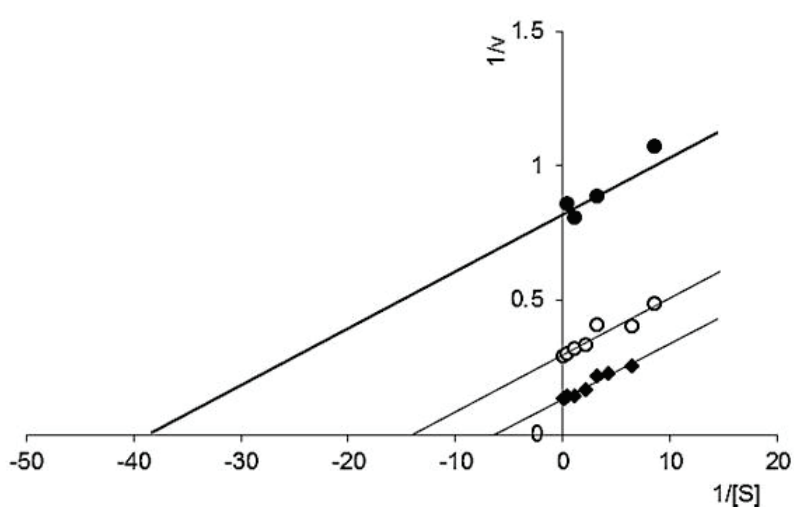

Fig. 2. Inhibitory effect of setipiprant on rat lens aldose reductase. Typical double reciprocal plots of the initial enzyme velocity vs. concentration of substrate ( $D, L$-glyceraldehyde) in the presence or absence of setipiprant: ( $\mathbf{})$ no inhibitor, (०) $0.1 \mu \mathrm{M},(\bullet) 0.2 \mu \mathrm{M}$ setipiprant (uncompetitive type of inhibition, $\mathrm{Ki}=0.065 \pm 0.020 \mu \mathrm{M})$.

\section{Discussion}

The double-reciprocal plot comprising parallel lines with apparently decreasing $\mathrm{V}_{\max }$ and $\mathrm{K}_{\mathrm{m}}$ values with increasing setipiprant concentrations indicates that this drug inhibits aldose reductase in an uncompetitive manner. This means that setipiprant may exert its inhibitory effect by binding to the E-NADP ${ }^{+}$complex in 


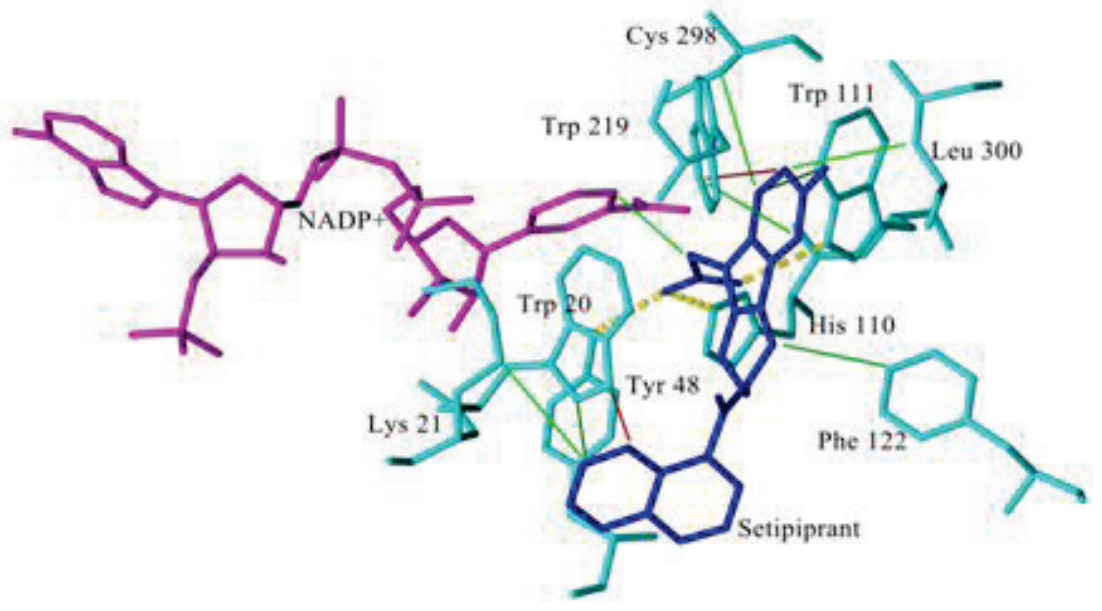

Fig. 3. Binding mode of setipiprant (dark blue) with human aldose reductase (AKR1B1 - pdb model $1 z 3 n$, cyan) and $\mathrm{NADP}^{+}$ (magenta). The oxygen atoms of the carboxylate group of the inhibitor form H-bonds to Tyr 48, His 110 and Trp 111 (yellow dashed lines). The position of setipiprant is stabilized by hydrophobic (green) and $\pi-\pi$ (red) interactions. the way the other negatively charged aldose reductase inhibitors do (Bohren and Grimshaw 2000). Uncompetitive type of inhibition was proved for another indole-1-acetic acid derivative, sulindac (Zheng et al. 2012).

Molecular docking simulations into the aldose reductase inhibitor binding site revealed an interaction pattern of setipiprant with the enzyme which resembled that of structurally related lidorestat. On binding of these inhibitors to the aldose reductase binding site, a conformational change occurs, opening a pocket localized between Trp 111 and Leu 300 (Urzhumtsev et al. 1997). Since the residues lining this pocket are not conserved in aldehyde reductase, the interactions are specific for aldose reductase (El-Kabbanii et al. 1998, Sotriffer et al. 2004) resulting in high selectivity. For setipiprant, the selectivity is characterized by a factor exceeding the value of 300 .

The inflammation is a complex process of a multifactorial etiology which may be initiated by a variety of primary events. Recent studies revealed the role of reactive oxygen species and lipid peroxides in the etiology of asthma (Paredi et al. 2000, Rahman et al. 2002, Wood et al. 2003, Yadav and Saini 2016). Increased levels of hydroperoxides have been reported during senescence (Lippman 1985, Spiteller 2007, Trueb 2009, Yavuzer et al. 2016).

Lipid peroxidation products, namely toxic aldehydes, are considered important mediators of the inflammation process initiated by reactive oxygen species. Aldose reductase was found to reduce peroxidation derived lipid aldehydes, such as 4-hydroxytrans-2-nonenal (HNE) and their glutathione conjugates (e.g. GS-HNE), to corresponding alcohols, 1,4-dihydroxy-nonene (DHN) and glutathionyl-1,4dihydroxynonene (GS-DHN), respectively, which take part in the inflammation signaling. The reduced aldehyde glutathione conjugate GS-DHN is considered a novel signaling intermediate in the transduction of reactive oxygen species initiated cell signals, leading eventually to inflammation response (Srivastva et al. 2011).

As a matter of fact, the key step of the inflammation cascade initiated by reactive oxygen species/lipid hydroperoxides is dependent on aldose reductase, an essential component of the physiological detoxification system. Inhibition of aldose reductase was found to prevent significantly the transfer of the inflammatory signals induced by multiple factors including allergens, cytokines, growth factors, endotoxins, high glucose, and autoimmune reactions at the cellular level as well as in animal models (Srivastava et al. 2011, Ramana and Srivastava 2010). Aldose reductase inhibitors thus present a promising therapeutic approach to deal with a number of inflammatory diseases such as asthma (Ramana et al. 2011, Yadav et al. 2009, Yadav et al. 2011, Yadav et al. 2013), uveitis (Yadav et al. 2007, Yadav et al. 2010, Di Fillipo 2014), sepsis (Reddy et al. 2009, Pandey 2012), periodontitis (Kador et al. 2011) and other injuries that have the potential of stimulating the immune system and generating large amounts of inflammatory cytokines and chemokines. The ability of setipiprant to inhibit efficiently aldose reductase-mediated reduction of $\mathrm{HNE}$ and its physiological adduct GS-HNE thus represents a plausible mechanism which may contribute to the anti-inflammatory action of setipiprant.

Recently, Nagata et al. (2011) reported catalytic activity of AKR1B1 in isomerization of PGH2 to PGD2 in the absence of NADPH. In the view of our findings revealing the inhibitory action of setipiprant on NADPH-dependent reduction of PGH2 by AKR1B1, we hypothesize that setipiprant may affect the production of PGD2 via NADPH-independent isomerization of $\mathrm{PGH} 2$ 
as well. Of course, this hypothesis needs experimental proof which was beyond the scope of this report.

\section{Conclusions}

Aldose reductase inhibitory action of setipiprant was proved and molecular docking simulations into the aldose reductase inhibitor binding site revealed an interaction pattern of setipiprant with the enzyme. Considering multifactorial etiology of inflammatory disorders, it is suggested that, in addition to the antagonizing prostaglandin D2 receptor, inhibition of aldose reductase may contribute to the reported anti-inflammatory action of setipiprant.

\section{Conflict of Interest}

There is no conflict of interest.

\section{Acknowledgements}

M.S. acknowledges Prof. G. Klebe, Philipps-University Marburg for providing recombinant human aldose reductase AKR1B1 enzyme. This work was supported by VEGA 2/0041/15 and VEGA 2/0033/14. We also thank the Slovak Research and Development Agency under the contract No. APVV-15-0455 and SAS - TÜBİTAK Joint Project No. JRP 2015/7 for funding.

\section{References}

BALENDIRAN GK, RAJKUMAR B: Fibrates inhibit aldose reductase activity in the forward and reverse reactions. Biochem Pharmacol 70: 1653-1663, 2005.

BOHREN KM, GRIMSHAW CE: The sorbinil trap: a predicted deadend complex confirms the mechanism of aldose reductase inhibition. Biochemistry 39: 9967-9974, 2000.

COTSARELIS G, FITZGERALD G, GARZA L: Compositions and methods for regulating hair growth. US Patent application 2015/0072963, 2015.

DIAMANT Z, SIDHARTA PN, SINGH D, O'CONNOR BJ, ZUIKER R, LEAKER BR, SILKEY M, DINGEMANSE $\mathrm{J}$ : Setipiprant, a selective CRTH2 antagonist, reduces allergen-induced airway responses in allergic asthmatics. Clin Exp Allergy 44: 1044-1052, 2014.

Di FILIPPO C, ZIPPO MV, MAISTO R, TROTTA MC, SINISCALCO D, FERRARO B, FERRARACCIO F, LA MOTTA C, SARTINI S, COSCONATI S, NOVELLINO E, GESUALDO C, SIMONELLI F, ROSSI S, D'AMICO M: Inhibition of ocular aldose reductase by a new benzofuroxane derivative ameliorates rat endotoxic uveitis. Mediators Inflamm 2014: 857958, 2014.

EL-KABBANI O, WILSON DK, PETRASH J M, QUIOCHO FA: Structural features of the aldose reductase and aldehyde reductase inhibitor-binding sites. Mol Vis 4: 19, 1998.

ENDO S, MATSUNAGA T, MAMIYA H, HARA A, KITADE Y, TAJIMA K, EL-KABBANI O: Characterization of a rat NADPH-dependent aldo-keto reductase (AKR1B13) induced by oxidative stress. Chem Biol Interact 178: 151-157, 2009.

FRETZ H, VALDENAIRE A, POTHIER J, HILPERT K, GNERRE C, PETER O, LEROY X, RIEDERER MA: Identification of 2-(2-(1-naphthoyl)-8-fluoro-3,4-dihydro-1H-pyrido[4,3-b]indol-5(2H)-yl)acetic acid (setipiprant/ACT-129968), a potent, selective, and orally bioavailable chemoattractant receptor-homologous molecule expressed on Th2 cells (CRTH2) antagonist. J Med Chem 56: 4899-4911, 2013.

GARZA LA, LIU Y, YANG Z, ALAGESAN B, LAWSON JA, NORBERG SM, LOY DE, ZHAO T, BLATT HB, STANTON DC, CARRASCO L, AHLUWALIA G, FISCHER SM, FITZGERALD GA, COTSARELIS G: Prostaglandin D2 inhibits hair growth and is elevated in bald scalp of men with androgenetic alopecia. Sci Transl Med 4: 126ra34, 2012.

JUSKOVA M, MAJEKOVA M, DEMOPOULOS V, STEFEK M: Substituted derivatives of indole acetic acid as aldose reductase inhibitors with antioxidant activity: structure-activity relationship. Gen Physiol Biophys 30: 342-349, 2011.

KABUTUTU Z, MANIN M, POINTUD JC, MARUYAMA T, NAGATA N, LAMBERT S, LEFRANÇOISMARTINEZ AM, MARTINEZ A, URADE Y: Prostaglandin F2alpha synthase activities of aldo-keto reductase 1B1, 1B3 and 1B7. J Biochem 145: 161-168, 2009.

KADOR PF, O'MEARA JD, BLESSING K, MARX DB, REINHARDT RA: Efficacy of structurally diverse aldose reductase inhibitors on experimental periodontitis in rats. J Periodontol 82: 926-933, 2011. 
KAISEROVA K, SRIVASTAVA S, HOETKER JD, AWE SO, TANG X-L, CAI J, BHATNAGAR A: Redox activation of aldose reductase in the ischemic heart. J Biol Chem 281: 15110-15120, 2006.

KRIEGER E, KORAIMANN G, VRIEND G: Increasing the precision of comparative models with YASARA NOVA a self-parameterizing force field. Proteins 47: 393-402, 2002.

LIPPMAN RD: Rapid in vivo quantification and comparison of hydroperoxides and oxidized collagen in aging mice, rabbits and man. Exp Gerontol 20: 1-5, 1985.

NAGATA N, KUSAKARI Y, FUKUNISHI Y, INOUE T, URADE Y: Catalytic mechanism of the primary human prostaglandin F2 $\alpha$ synthase, aldo-keto reductase 1B1 - prostaglandin D2 synthase activity in the absence of NADP(H). FEBS J 278: 1288-1298, 2011.

NORMAN P: Update on the status of DP2 receptor antagonists; from proof of concept through clinical failures to promising new drugs. Expert Opin Investig Drugs 23: 55-66, 2014.

PANDEY S, SRIVASTAVA SK, RAMANA KV: A potential therapeutic role for aldose reductase inhibitors in the treatment of endotoxin-related inflammatory diseases. Expert Opin Investig Drugs 21: 329-339, 2012.

PAREDI P, KHARITONOV SA, BARNES PJ: Elevation of exhaled ethane concentration in asthma. Am J Respir Crit Care Med 162: 1450-1454, 2000.

RAHMAN I, VAN SCHADEWIJK AA, CROWTHER AJ, HIEMSTRA PS, STOLK J, MACNEE W, DE BOER WI: 4-Hydroxy-2-nonenal, a specific lipid peroxidation product, is elevated in lungs of patients with chronic obstructive pulmonary disease. Am J Respir Crit Care Med 166: 490-495, 2002.

RAMANA KV, SRIVASTAVA SK: Aldose reductase: a novel therapeutic target for inflammatory pathologies. Int $J$ Biochem Cell Biol 42: 17-20, 2010.

RAMANA KV, YADAV UC, CALHOUN WJ, SRIVASTAVA SK: Current prospective of aldose reductase inhibition in the therapy of allergic airway inflammation in asthma. Curr Mol Med 11: 599-608, 2011.

REDDY AB, SRIVASTAVA SK, RAMANA KV: Anti-inflammatory effect of aldose reductase inhibition in murine polymicrobial sepsis. Cytokine 48: 170-176, 2009.

SHAO Y, MOLNAR L-F, JUNG Y, KUSSMANN J, OCHSENFELD C, BROWN ST, GILBERT AT, SLIPCHENKO LV, LEVCHENKO SV, O'NEILL DP, DISTASIO RA JR, LOCHAN RC, ET AL.: Advances in methods and algorithms in a modern quantum chemistry program package. Phys Chem Chem Phys 8: 3172-3191, 2006.

SOTRIFFER C, KRÄMER O, KLEBE G: Probing flexibility and "induced-fit" phenomena in aldose reductase by comparative crystal structure analysis and molecular dynamics simulations. Proteins 56: 52-66, 2004.

SPITELLER G: The important role of lipid peroxidation processes in aging and age dependent diseases. Mol Biotechnol 37: 5-12, 2007.

SRIVASTAVA S, CHANDRA A, WANG L-F, SEIFERT WE JR, DAGUE BB, ANSARI NH, SRIVASTAVA SK, BHATNAGAR A: Metabolism of the lipid peroxidation product, 4-hydroxy-trans-2-nonenal, in isolated perfused rat heart: J Biol Chem 273: 10893-10900, 1998.

SRIVASTAVA SK, YADAV UC, REDDY AB, SAXENA A, TAMMALI R, SHOEB M, ANSARI NH, BHATNAGAR A, PETRASH MJ, SRIVASTAVA S, RAMANA KV: Aldose reductase inhibition suppresses oxidative stress-induced inflammatory disorders. Chem Biol Interaction 191: 330-338, 2011.

STEFEK M, SNIRC V, DJOUBISSIE P-O, MAJEKOVA M, DEMOPOULOS V, RACKOVA L, BEZAKOVA Z, KARASU C, CARBONE V, EL-KABBANI O: Carboxymethylated pyridoindole antioxidants as aldose reductase inhibitors: synthesis, activity, partitioning, and molecular modelling. Bioorg Med Chem 16: 4908-4920, 2008.

STEFEK M, SOLTESOVA PRNOVA M, MAJEKOVA M, RECHLIN C, HEINE A, KLEBE G: Identification of novel aldose reductase inhibitors based on carboxymethylated mercaptotriazinoindole scaffold. J Med Chem 58: 2649-2657, 2015.

TRUEB RM: Oxidative stress in ageing of hair. Int J Trichology 1: 6-14, 2009.

URZHUMTSEV A, TETE-FAVIER F, MITSCHLER A, BARBANTON J, BARTH P, URZHUMTSEVA L, BIELLMANN J-F, PODJARNY AD, MORAS DA: A 'specificity' pocket inferred from the crystal structures of the complexes of aldose reductase with the pharmaceutically important inhibitors tolrestat and sorbinil. Structure 5: 601-612, 1997. 
VAN ZANDT MC, JONES ML, GUNN DE, GERACI LS, JONES JH, SAWICKI DR, SREDY J, JACOT JL, DICIOCCIO AT, PETROVA T, MITSCHLER A, PODJARNY AD: Discovery of 3-[(4,5,7-trifluorobenzothiazol-2-yl)methyl]indole-N-acetic acid (lidorestat) and congeners as highly potent and selective inhibitors of aldose reductase for treatment of chronic diabetic complications. J Med Chem $\mathbf{4 8}$ : 3141-3152, 2005.

VAN ZANDT MC, DOAN B, SAWICKI DR, SREDY J, PODJARNY AD: Discovery of [3-(4,5,7-trifluorobenzothiazol-2-ylmethyl)-pyrrolo[2,3-b]pyridin-1-yl]acetic acids as highly potent and selective inhibitors of aldose reductase for treatment of chronic diabetic complications. Bioorg Med Chem Lett 19: 2006-2008, 2009.

WOOD LG, GIBSON PG, GARG ML: Biomarkers of lipid peroxidation, airway inflammation and asthma. Eur Respir J 21: 177-186, 2003.

YADAV AS, SAINI M: Evaluation of systemic antioxidant level and oxidative stress in relation to lifestyle and disease progression in asthmatic patients. J Med Biochem 35: 55-62, 2016.

YADAV UC, SRIVASTAVA SK, RAMANA KV: Aldose reductase inhibition prevents endotoxin-induced uveitis in rats. Invest Ophthalmol Vis Sci 48: 4634-4642, 2007.

YADAV UC, RAMANA KV, AGUILERA-AGUIRRE L, BOLDOGH I, BOULARES HA, SRIVASTAVA SK: Inhibition of aldose reductase prevents experimental allergic airway inflammation in mice. PLoS One 4: e6535, 2009.

YADAV UCS, SRIVASTAVA SK, RAMANA KV: Understanding the role of aldose reductase in ocular inflammation. Curr Mol Med 10: 540-549, 2010.

YADAV UCS, RAMANA KV, SRIVASTAVA SK: Aldose reductase inhibition suppresses airway inflammation. Chem Biol Interact 191: 339-345, 2011.

YADAV UC, NAURA AS, AGUILERA-AGUIRRE L, BOLDOGH I, BOULARES HA, CALHOUN WJ, RAMANA $\mathrm{KV}$, SRIVASTAVA SK: Aldose reductase inhibition prevents allergic airway remodeling through PI3K/AKT/GSK3 $\beta$ pathway in mice. PLoS One 8: e57442, 2013.

YAVUZER H, YAVUZER S, CENGIZ M, ERMAN H, DOVENTAS A, BALCI H, ERDINCLER DS, UZUN H: Biomarkers of lipid peroxidation related to hypertension in aging. Hypertens Res 39: 342-348, 2016.

ZHENG X, ZHANG L, ZHAI J, CHEN Y, LUO H, HU X: The molecular basis for inhibition of sulindac and its metabolites towards human aldose reductase. FEBS Lett 586: 55-59, 2012. 